\title{
Evaluation of Energy Efficiency in a Grain Unloading Platform
}

\author{
João Luiz Fontana de Figueiredo ${ }^{1}$, Carlos Eduardo Camargo Nogueira ${ }^{1}$, Thaís Caroline Gazola ${ }^{1}$, \\ Alfredo Petrauski ${ }^{1}$, Jair Antonio Cruz Siqueira ${ }^{1} \&$ Samuel Nelson Melegari de Souza ${ }^{1}$ \\ ${ }^{1}$ State University of Western Paraná, Cascavel Campus, Paraná, Brazil \\ Correspondence: João Luiz Fontana de Figueiredo, State University of Western Paraná, Cascavel Campus, \\ Paraná, Brazil. E-mail: jota_fontana@hotmail.com
}

Received: August 20, 2018

doi:10.5539/jas.v10n12p511
Accepted: September 20, $2018 \quad$ Online Published: November 15, 2018

URL: https://doi.org/10.5539/jas.v10n12p511

\begin{abstract}
This paper aims to conduct an energy efficiency study in the tipping system of the unloading platform of a grain storage unit, based on the use of electrical devices to control the operation of the engine. For this purpose, two scenarios were established. The first scenario considers the platform in its current state, with engine start-up performed using a wye-delta switch. In the second scenario, wye-delta start is switched off, and a frequency inverter and a programmable logic controller (PLC) are coupled to control the electric motor. For both scenarios, the consumption of active and reactive energy in the discharge platform was measured, and the costs of the energy consumed were calculated over a period of one year. Finally, the discounted payback was calculated to evaluate the economic feasibility of installing the proposed equipment. The results obtained were as follows: For the current scenario, the energy consumed to tipping one metric ton of grain was $35.44 .10^{-3} \mathrm{kWh}$; for the proposed scenario with the frequency inverter, the energy was $32.78 .10^{-3} \mathrm{kWh}$. With an annual projection, the current scenario would consume the equivalent of $10921.35 \mathrm{kWh}$, and the proposed scenario, $10100.81 \mathrm{kWh}$, generating an annual savings, with the installation of the equipment, of R $\$ 721.49$; the discounted payback found was approximately 31 years. It can thus be concluded that there is a reduction in electricity consumption from the use of the frequency inverter; however, the time of return of the invested capital is very long, making the proposal economically unfeasible.
\end{abstract}

Keywords: agroindustry, grain unloading platform, frequency inverter

\section{Introduction}

Mankind learned to master fire in the Paleolithic period, over 10000 years ago. Since then, man has benefited from a reliable source of heat and light, altering its history. Unfortunately, almost nothing has changed for one out of three people in the world today. It is estimated that there are still more than 1.5 billion people in the world without access to electricity, and this is one of the most important issues for quality of life and human development (UN, 2010).

Access to clean, efficient and renewable energy is indispensable for global growth. Developed countries must expand access to more modern types of energy in order to reduce poverty, improve and provide more health for citizens while accelerating production and promoting global growth.

In this line of reasoning, mankind must pursue two paths; first: the development of new forms of generating and supplying electricity; second: rationalization in the use of this energy, so that this resource is available to people who do not yet have it.

The processing of agricultural products requires high electricity consumption, due to the need to store such products. Moreover, the lack of investment in more efficient equipment makes consumption inefficient.

Grain production is performed on a seasonal basis, the volume harvested in these periods being greater than consumption. Based on that, it becomes necessary to store and preserve them, so that they can be traded in the future, according to the convenience of the market. This use becomes effective thanks to the scarcity of such a product on the market or through the business strategy of storage companies. The agri-industrial grain market revolves around this infrastructure of grain storage and processing, which is responsible for the largest economy in Brazil (Portal Brasil, 2017). 
Brazil is currently the second largest producer of soybeans and one of the largest grain producers in the world. According to the latest survey of the 2016/2017 harvest, Brazil is expected to beat all previous records of productivity (EMBRAPA, 2017).

The official estimate issued is 237.22 million metric tons, accounting for a growth of $27.1 \%$ in relation to the 2015/2016 harvest. The planted area is estimated at 60.49 million hectares, with an estimated growth of $3.7 \%$, which shows that the increase in production was much more influenced by the efficiency of new technologies than the area of planting itself. Thus, the country has been gaining prominence, crop after crop, and claiming the title of the "world's granary" (CONAB, 2017).

Because it is a tropical country, Brazil relies heavily on quality storage to preserve grain and offer flexibility to companies to meet the demands of the market. In terms of storage, Brazil's static capacity as of 2016 is 157.62 million metric tons. It is observed that the storage capacity is below production, which implies an even greater need for speed in receiving and shipping this grain (CONAB, 2017).

Grain storage units are equipped with a platform called truck lift, which is responsible for removing the product from inside the trucks and referring it for processing and storage. This equipment operates by tipping the truck with the aid of gravity, and all material is drained into hoppers. At harvest times, the equipment operates 24 hours a day, 7 days a week, for the duration of the harvest, so that its use can extend for several weeks. The energy propellant, responsible for elevating this platform, is a three-phase induction motor, which operates uninterruptedly throughout the mentioned period. Nevertheless, when analyzing a truck unloading cycle, the amount of time during which the use of this energy is required represents about $50 \%$ of the cycle time, since there is a need for power only during the elevation of the assembly, as gravity is responsible for the descent, and the time of ascent and descent is virtually the same. That is, during the entire period in which the equipment descends to its initial position, it can be said that there is a waste of energy.

This problem is addressed in this study. The proposed solution to minimize such loss of power would be to control the power of the electric motor with the use of a Frequency Inverter and a Programmable Logic Controller (PLC), making some initial investments necessary. Nevertheless, there is an expectation of savings in the costs of the energy consumed, and to quantify this economy, the discounted payback model, which indicates the time of return of the capital invested, was used.

Therefore, this paper aims to make a technical and economical evaluation of energy efficiency in a hydraulic pump unit, driven by a three-phase induction motor, applied to a grain unloading platform, called a truck lift. The study proposes the installation of a frequency inverter and a PLC to control and reduce the energy consumed by the induction motor.

\section{Material and Methods}

This work was carried out in October and November of 2017, at AB Agrobrasil, located in the city of Cascavel, PR. The geographical coordinates of the unit are: $24^{\circ} 59^{\prime} 24.5^{\prime \prime} \mathrm{S}$ and $53^{\circ} 19^{\prime} 19.0^{\prime \prime} \mathrm{W}$.

For a better understanding, the measurements were divided into three topics: Electrical Devices; Hydraulic Devices; and Mechanical Devices.

\subsection{Electrical Devices}

In order to measure the electricity values, an RE7080 Energy Analyzer, by the Embrasul brand, was used to read the Voltage (V), Current (A), Power (kVA, kW, and kVAr), and Power Factor. The device is capable of measuring and storing this data for a detailed analysis of the results. The readings were stored every 200 milliseconds and were performed during the grain unloading period.

Table 1 shows the technical specifications of the equipment. 
Table 1. Technical specifications of the RE7080 model energy analyzer

\begin{tabular}{ll}
\hline Voltage Inputs & \\
\hline Number of Inputs & 3 (VA, VB, VC) or 4 (VA, VB, VC, VN) \\
Measurement Range & $50-300 \mathrm{Vac}$ (Phase-Neutral) and 519V (Phase-Phase) \\
Resolution & $0.01 \mathrm{~V}$ \\
Precision & $0.20 \%$ \\
Input Impedance & $2 \mathrm{M}$ \\
Bandwidth & $1500 \mathrm{~Hz}$ \\
\hline Current Inputs & \\
\hline Number of Inputs & $3(\mathrm{IA}, \mathrm{IB}, \mathrm{IC})$ or 4 (IA, IB, IC, IN) \\
Type & Flexible sensor \\
Measurement Range & $5-3000 \mathrm{~A}$ \\
Resolution & $0.01^{\mathrm{a}}$ \\
Precision & $0.20 \%$ \\
Bandwidth & $1500 \mathrm{~Hz}$ \\
\hline
\end{tabular}

\subsection{Hydraulic Devices}

The hydraulic devices, which make up the unloading platform, are the hydraulic unit, composed of a Parker gearbox hydraulic pump, 20300C 5N3 model; a valve block, used for driving the cylinders; and the hydraulic fluid reservoir. These are two parallel cylinders with four stages, and in each stage having a stroke of 1,731 mm, to a total stroke is $6,924 \mathrm{~mm}$.

For the measurement of the pressure $\left(\mathrm{kgf} / \mathrm{cm}^{2}\right)$ of the hydraulic assembly, the analog gauge of the equipment was used, located in the unloading platform in question. The values obtained were compared with the data provided by the manufacturer, as shown in Table 2 .

Table 2. Technical specifications provided by the manufacturer

\begin{tabular}{ll}
\hline Rear Unloading Platform, 21 meters & \\
\hline Battery capacity & 90 metric tons \\
Length & 21 meters \\
Platform weight & 20 metric tons \\
Width & 3 meters \\
Tilt angle & $40^{\circ}$ \\
Pump flow & $180 \mathrm{lpm}$ \\
Maximum pressure & $190 \mathrm{bar}$ \\
Electric power of the motor & $50 \mathrm{cv}$ \\
Electric voltage of the motor & $380 \mathrm{Vac}$ \\
\hline
\end{tabular}

Source: SAUR (2017).

\subsection{Mechanical Devices}

The mechanical devices are composed of the discharge platform and the AB Agrobrasil truck scale.

The data for the unloading platform are shown in Table 2.

The truck scale, installed at the unit, is of the Balanças Capital brand, BC CONTROLLER 3.0 model, certified by INMETRO. With it, the total weight of the truck was obtained, before and after unloading the product, making it possible to determine the weight of the product unloaded.

\subsection{Methodology}

The Mechanical Power, used to tip the platform, is given by Equation 1.

$$
\mathrm{Pm} 2=\mathrm{F} \cdot \mathrm{v}
$$

Where, $\operatorname{Pm} 2=$ Mechanical Power $(\mathrm{W}) ; \mathrm{F}=$ Force required to lift the platform $(\mathrm{N}) ; v=\operatorname{Speed}(\mathrm{m} / \mathrm{s})$. 


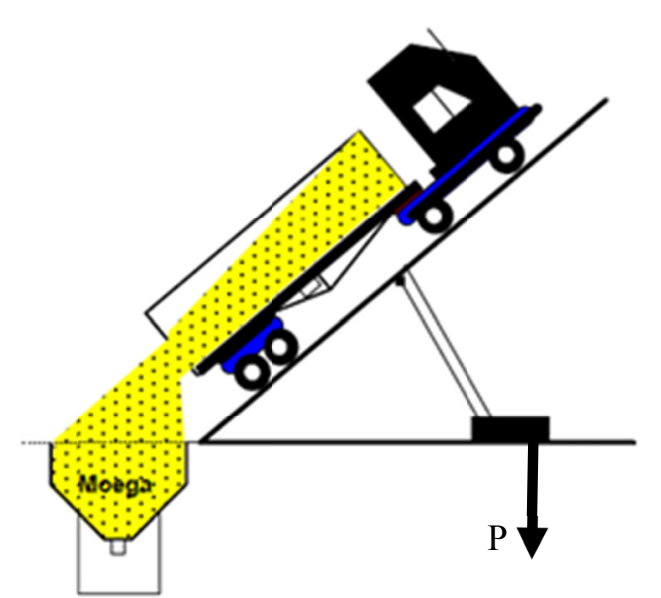

Figure 1. Force truck weight loaded plus platform

Source: Silva, 2010.

The calculation of the Force is based on the weight of the platform and the loaded truck, as well as the acceleration of gravity. For the calculation of the force, the Equation 2 is used:

$$
\mathrm{F}=\mathrm{m} \cdot \mathrm{g}
$$

Where, $\mathrm{F}=$ Force $(\mathrm{N}) ; \mathrm{m}=$ mass $(\mathrm{kg}) ; \mathrm{g}=$ acceleration of gravity $\left(9.8 \mathrm{~m} / \mathrm{s}^{2}\right)$.

To calculate the speed of power, the speed formula, Equation 3:

$$
\mathrm{v}=\mathrm{CC} / \mathrm{t}
$$

Where, $\mathrm{CC}=$ Cylinder Stroke $(\mathrm{m}) ; \mathrm{t}=$ opening time of the cylinder(s).

The Hydraulic Power, required to provide the mechanical power of the platform, is given by Equation 4 :

$$
\mathrm{Ph}=1,405 \cdot \mathrm{Q} \cdot \mathrm{Pre}
$$

Where, $\mathrm{Ph}=$ Hydraulic Power of the pump (W); $\mathrm{Q}=$ Flow $(\mathrm{l} / \mathrm{min})$; Pre $=$ Pressure $\left(\mathrm{kgf} / \mathrm{cm}^{2}\right)$.

The mechanical power of the motor, required to provide the power of the hydraulic pump, is given by Equation $5:$

$$
\operatorname{Pm} 1=\text { Pel·n'motor }
$$

Where, Pm1 = Mechanical Power of the motor (W); Pel = Electric Power (W); $\eta$ motor $=$ Motor efficiency.

The Electric Power to drive the electric motor is presented in Equation 6:

$$
\mathrm{Pel}=\sqrt{3} \cdot \mathrm{V} \cdot \mathrm{I} \cdot \cos \varphi
$$

Where, $\mathrm{V}=$ Voltage $(\mathrm{V}) ; \mathrm{I}=$ Current $(\mathrm{A}) ; \cos \varphi=$ Power Factor.

The yields of the platform control devices were calculated according to Equations 7, 8, and 9:

$$
\begin{gathered}
\eta \text { platform }=\mathrm{Pm} 2 / \mathrm{Ph} \\
\eta \text { hydralic pump }=\mathrm{Ph} / \mathrm{Pm} 1 \\
\eta \text { total }=\mathrm{n} \text { platform } \cdot \mathrm{n} \text { hydraulic pump } \cdot \mathrm{n} \text { motor }
\end{gathered}
$$

Where, $\mathrm{n}$ platform $=$ Mechanical platform yield; $\eta$ hydraulic pump $=$ Hydraulic pump yield $\eta \eta$ total $=$ Total yield of the platform drive assembly.

\subsection{Scenarios Evaluated}

Scenario 1: It is characterized by the original configuration of the tipping system, without the installation of the control equipment. In this scenario, electric, hydraulic and mechanical quantities were collected to evaluate the initial conditions of operation of the system (wye-delta start).

To measure the electrical quantities, the Energy Analyzer was installed in the three phases (R, S, and T) of the motor control panel. The installed equipment follows the correct order of the TPs and CTs, which will be connected in their respective phases, as shown in Figure 2. 


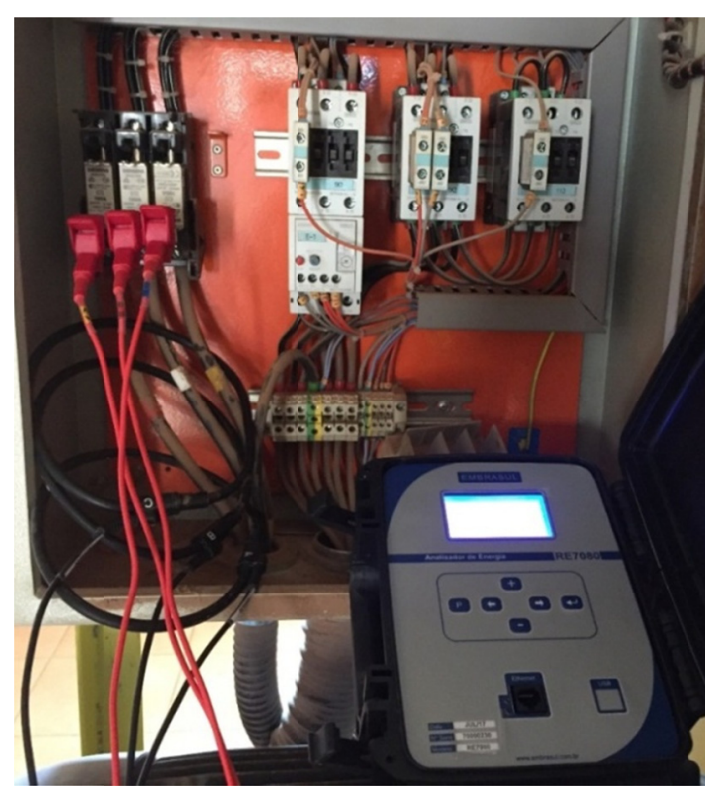

Figure 2. Electrical control panel of the hydraulic unit with power analyzer installed

The equipment installed and the data records were made while there were trucks to unload products onto the platform, in order to verify the powers demanded by the three-phase induction motor. The energy analyzer was parameterized to perform measurements in 200 -ms intervals.

The hydraulic quantities, which are required to calculate the power of the hydraulic unit, are hydraulic pressure, obtained from the reading of the manometer installed in the pump, and fluid flow, obtained from the manufacturer's catalog (Table 2).

The mechanical magnitudes, required to calculate the mechanical power used in the platform, are the platform, truck and product weights, cylinder lengths, and lifting time. The weights were collected from all the trucks that performed the unloading on the platform. The truck was weighed, first loaded, newly arrived at the station, and again, after unloading, completely empty.

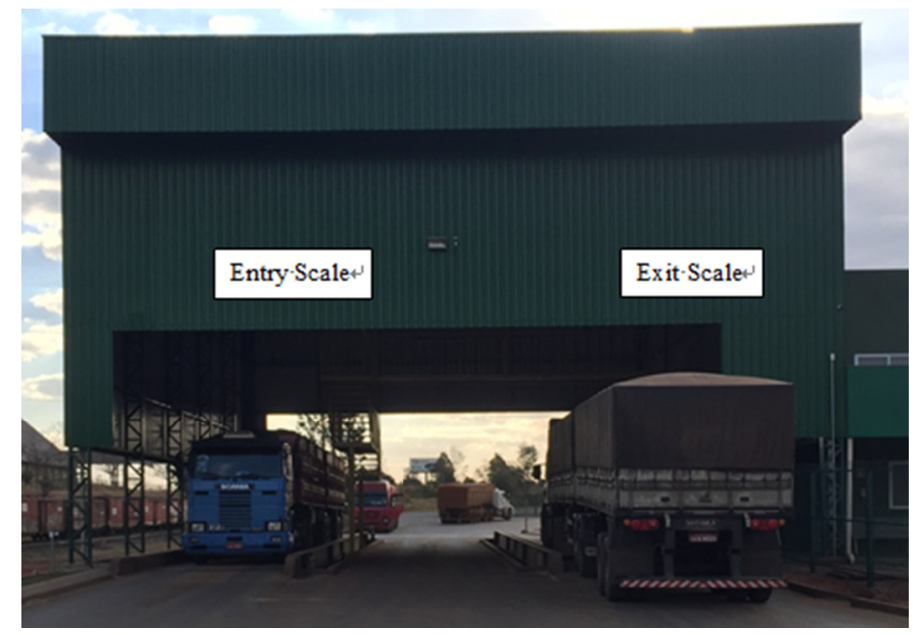

Figure 3. Entry and exit scale of the AB Agrobrasil storage unit 
The weights used in the calculations followed the following legend:

\begin{tabular}{|l|l|}
\hline PBT & Total Gross Weight (PC+PL) \\
\hline PC & Truck Weight \\
\hline PL & Net Weight (PBT+PC) \\
\hline PP & Platform Weight \\
\hline PT & Total Weight (PBT+PP) \\
\hline
\end{tabular}

On October 27, 2017, at 8:28 am, measurements were started for the conventional wye-delta starting system. Five (5) trucks were unloaded in a row, all with wheat, with the last truck leaving the platform at 9:36 am, completing the recording of the energy analyzer. The analyzer data was uploaded to the computer for analysis, and the weights of the trucks, whose plates were recorded, were reported by AB Agrobrasil, according to Table 3 .

Table 3. Weights of the trucks under study for scenario 1

\begin{tabular}{llll}
\hline Truck & PBT (metric ton) & PC (metric ton) & PL (metric ton) \\
\hline$A$ & 54.26 & 16.50 & 37.76 \\
$B$ & 53.86 & 16.62 & 37.24 \\
$C$ & 51.14 & 16.92 & 34.22 \\
$D$ & 55.38 & 16.32 & 39.06 \\
$E$ & 33.28 & 10.64 & 22.64 \\
\hline
\end{tabular}

For comparative purposes, a measurement unit was established by dividing the energy consumed during the measurement interval in $\mathrm{kWh}$ by the total weight of the analysis period, according to equation 10 . This total weight includes the PBT (weight of the loaded truck) plus the weight of the platform, which, according to the manufacturer, has 20 metric tons. Therefore:

$$
\mathrm{E} / \mathrm{T}=\mathrm{kWh} / \mathrm{PT}
$$

Where, $\mathrm{E} / \mathrm{T}=$ Energy per Metric Ton $(\mathrm{kWh} / \mathrm{ton}) ; \mathrm{kWh}=$ Energy spent in the measurement range; $\mathrm{PT}=$ Total Weight of the cycle, considering PBT plus platform weight.

This index shows the amount of energy consumed, in $\mathrm{kWh}$, per ton of product that the platform needs to lift. Based on this, it is possible to compare the two scenarios, regardless of the number of cycles, truck weight and time interval.

Scenario 2: It is characterized by the tipping system operating with the frequency inverter and the PLC, to control the induction electric motor. Similarly, in this scenario, electric, hydraulic and mechanical quantities were also collected to evaluate the operating conditions of the system.

To measure the electrical quantities, the Energy Analyzer was installed in the three phases (R, S, and T) of the motor control panel. The installed equipment follows the correct order of the TPs and CTs, which will be connected in their respective phases, before the frequency inverter, as shown in Figure 4. 


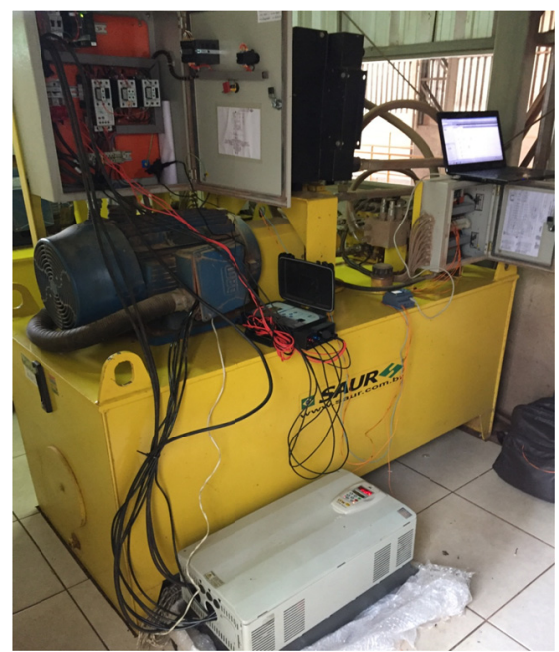

Figure 4. Electrical control panel of the hydraulic unit with power analyzer, installed with the frequency inverter

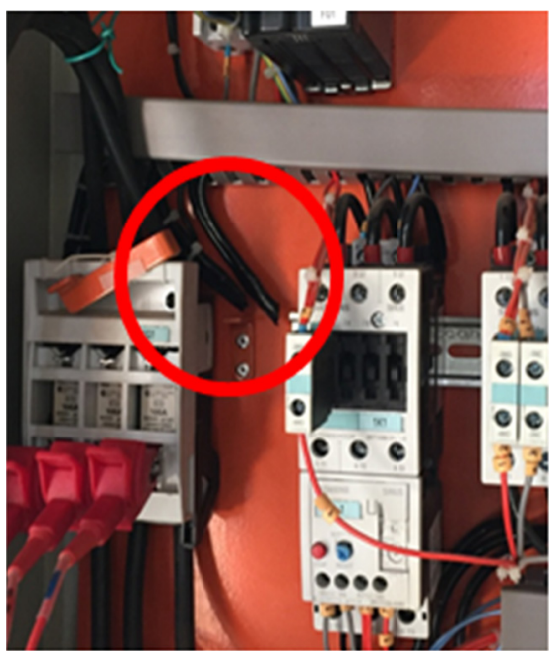

Figure 5. Cables of the wye-delta starter system disconnected

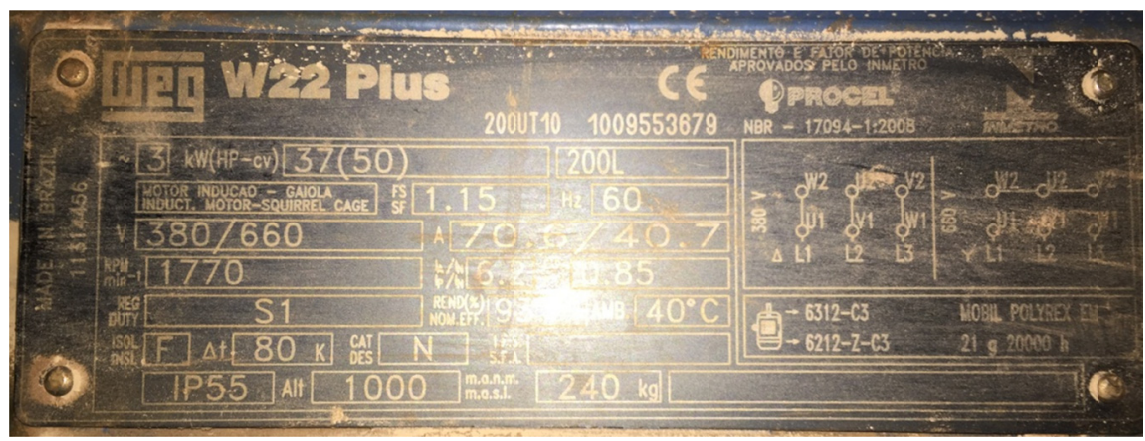

Figure 6. Motor nameplate

By avoiding interference in the $\mathrm{AB}$ Agrobrasil panel, the power cables for the wye-delta starter system were disconnected, as shown in Figure 5.

After disconnecting the cables, the frequency inverter was powered by an external branch and the motor cables were arranged in the triangle mode and connected to the frequency inverter according to the motor nameplate shown in Figure 6.

In order to control the frequency inverter, a Siemens PLC, Logo 8 model, was installed. This PLC has the role of monitoring the operation button and the limit switch of the platform, causing the inverter to be switched on or off as necessary.

The purpose of the frequency inverter application is to be able to switch off the electric motor at times when its use is not required. In view of this, a programming logic was developed on Ladder, in which the PLC monitored all buttons except the "down" button used to descend the platform, as that is precisely the moment at which the inverter is not used. By actuating any other button, the PLC triggers the inverter. To switch off the inverter, there were two conditions. The first one, due to button downtime: if, within 10 seconds, no button was pressed, the inverter was Switched off. This condition was observed during the experiment at times when the operator was performing tasks adjacent to the lift and the use of the hydraulic pump was not required, such as cleaning of surroundings, terminating some unit processes, etc. The second condition for the inverter shutdown was the combination of the "Lift Stroke End" and the "up" button, as this means that the platform has reached its maximum level, and the unit can be switched off, no longer requiring the hydraulic pump.

As the starting condition of the motor is evidenced by pressing any button on the panel, except for the "down" button, all operations requiring hydraulic pressure were satisfied with this condition, being a more efficient way to control the inverter. 
The power analyzer configuration parameters were kept exactly the same as the in first survey, with 200-ms intervals. The plates of the trucks were recorded for their respective weights.

After the installations and conditions described above, on November 11, 2017, at 2:09 pm, measurements were started for the starter system with the frequency inverter. Seven (7) trucks were unloaded in a row, all with corn, with the last truck leaving the platform at $3: 16 \mathrm{pm}$. The energy analyzer recording was then stopped. The analyzer data was uploaded to the computer for analysis, and the truck weights were reported by AB Agrobrasil, according to Table 4 .

Table 4. Weights of the trucks under study for scenario 2

\begin{tabular}{llll}
\hline Truck & PBT (metric ton) & PC (metric ton) & PL (metric ton) \\
\hline F & 48.26 & 16.08 & 32.18 \\
G & 48.10 & 16.62 & 31.48 \\
H & 48.06 & 16.50 & 31.56 \\
I & 48.36 & 16.32 & 32.04 \\
J & 48.36 & 16.40 & 31.96 \\
K & 48.16 & 16.66 & 31.50 \\
L & 48.22 & 16.08 & 32.14 \\
\hline
\end{tabular}

\subsection{Energy Index}

In order to enable a comparison with the measurements of the wye-delta starter system, the unit of energy by metric ton was extracted as shown above.

Based on the index created for comparison, previously presented, energy by weight ( $\mathrm{kWh} / \mathrm{ton})$, it is possible to compare the two systems. The lower value shows higher efficiency, as the index divides the amount of energy spent for a given time by the total weight tipped by the platform during the same time interval. Therefore, the system that presents the least amount of energy spent to lift one metric ton is the most efficient. With these two indices, it is possible to establish a percentage of efficiency of one with respect to the other.

Additionally, the cost of the components required to implement the frequency inverter starter system was evaluated in order to evaluate its economic feasibility.

In order to calculate the cost of energy avoided with the installation of the frequency inverter, it was necessary to obtain data referring to the cost of electricity that the company AB Agrobrasil paid to the electricity concessionaire (COPEL). Figure 7 shows one of these invoices.

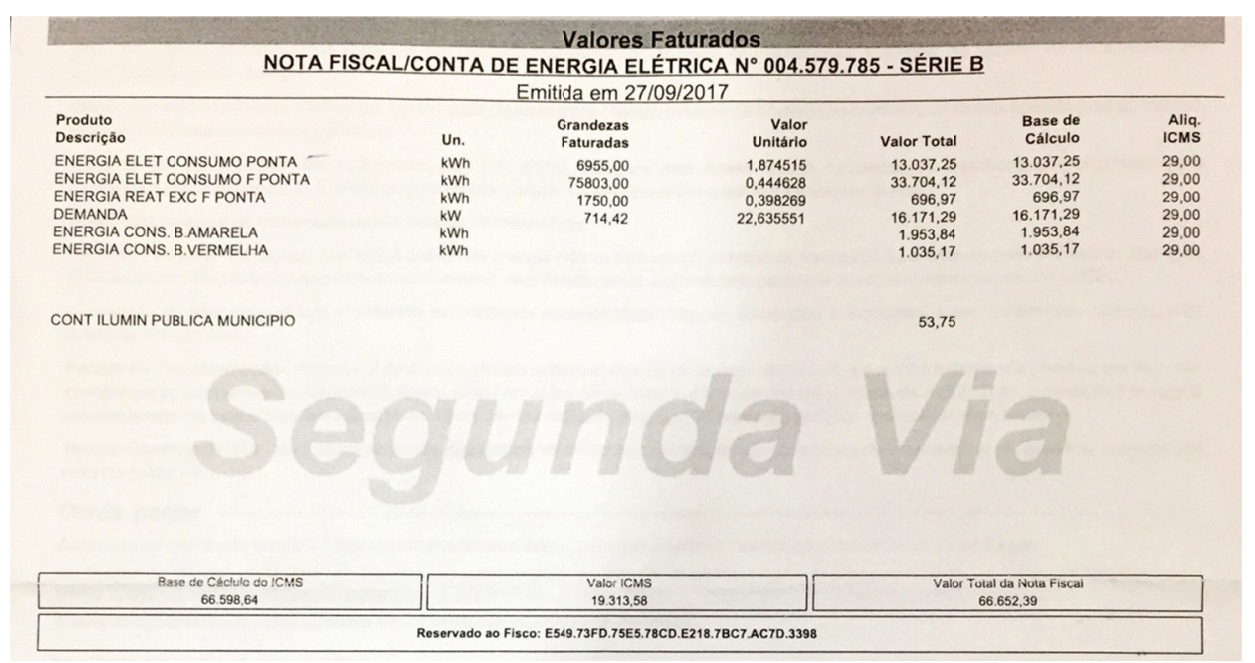

Figure 7. Electricity invoice issued by COPEL to AB Agrobrasil

Source: AB Agrobrasil (2017). 
As the energy data collected in the two scenarios were in off-peak hours, the total value of the energy bill was divided, considering all the tariff and tax variables, by the amount of active energy. In this way, a single tariff was created contemplating tariff and tax divisions, facilitating the estimated cost reduction according to equation 11 .

$$
\mathrm{TU}=\mathrm{VTF} / \mathrm{EAFP}
$$

Where, $\mathrm{TU}=$ Single Tariff $(\mathrm{R} \$ / \mathrm{kWh}) ; \mathrm{VTF}=$ Total Invoice Amount $(\mathrm{R} \$) ;$ EAFP $=$ Off-Peak Active Energy $(\mathrm{kWh})$.

To carry out the consumption reduction study, AB Agrobrasil informed the net weight of the products received for a period of one year, counting from October 2016 to September 2017 (month in which an energy invoice is submitted). These values are presented in Table 5.

Table 5. Net monthly weight of products received, from October 2016 to September 2017

\begin{tabular}{ll}
\hline Month & Received (metric ton) \\
\hline Oct/16 & 9407.06 \\
Nov/16 & 12837.68 \\
$\mathrm{Dec} / 16$ & 16735.33 \\
$\mathrm{Jan} / 17$ & 6509.60 \\
$\mathrm{Feb} / 17$ & 21120.50 \\
$\mathrm{Mar} / 17$ & 9135.70 \\
$\mathrm{Apr} / 17$ & 1713.98 \\
$\mathrm{May} / 17$ & 8732.40 \\
$\mathrm{Jun} / 17$ & 15780.14 \\
$\mathrm{Jul} / 17$ & 28114.16 \\
$\mathrm{Aug} / 17$ & 9134.98 \\
$\mathrm{Sep} / 17$ & 7769.38 \\
Total & $\mathbf{1 4 6 9 9 0 . 9 1}$ \\
\hline
\end{tabular}

Source: AB Agrobrasil (2017).

For the projection of the values obtained, the mean net weight of the measured values was calculated. The number of cycles in a month was estimated by dividing this mean Net Weight by the monthly receipt amount. This data was important because, for each cycle, 20 metric tons (Platform Weight) were added. In addition, the mean Truck Weight was calculated and added to the value of each cycle, enabling the determination of the Total Weight was tilted each month Equation 12).

$$
\text { PTmonth }=\text { PLmonth }+\left(\frac{\text { PLmonth }}{\text { PLmean }} \cdot \mathrm{PP}\right)+\left(\frac{\text { PLmonth }}{\text { PLmean }} \cdot \text { PCmean }\right)
$$

Where, PTmonth $=$ Total Weight tipped in the month (metric ton); PLmonth $=$ Net Weight in the month (metric ton); PLmean $=$ Mean Net Weight (metric ton); PP = Platform Weight (ton); PCmean $=$ Mean Truck Weight (metric ton).

After the definition of the Total Weight tipped monthly, the value was multiplied by the energy index by metric ton to obtain the total electricity consumed in each month by the unloading platform, in the current scenario and in the scenario with the frequency inverter (Equation 13).

$$
\mathrm{ECmonth}=\mathrm{PTmonth} \cdot \mathrm{E} / \mathrm{T}
$$

Where, ECmonth = Energy Consumed in the month $(\mathrm{kWh} /$ month); PTmonth $=$ Total Weight tilted in the month (metric ton/month); E/T = Energy per Metric Ton $(\mathrm{kWh} / \mathrm{ton})$.

This amount of energy was then multiplied by the Single Tariff (TU), in order to verify the amount spent on electricity consumed with the platform, for the two scenarios under study. The difference between these values and the monthly cost electricity avoided (Equation 14) was calculated. Subsequently, the annual cost avoided was also calculated.

$$
\text { Vmonth }=\text { ECmonth } \cdot \text { TU }
$$

Where, Vmonth = Amount paid in the month in energy for the unloading platform $(\mathrm{R} \$ /$ month); ECmonth $=$ Energy Consumed in the month $(\mathrm{kWh} / \mathrm{month}) ; \mathrm{TU}=$ Single Tariff $(\mathrm{R} \$ / \mathrm{kWh})$. 
Another benefit expected with the application of the frequency inverter starter system was the increased productivity, as this equipment allows an increase in nominal rotation of the motor by a certain percentage. For this experiment, a tipping was performed with the rotation $20 \%$ above the nominal rate. By measuring the time the platform took to reach its maximum level, it was possible to determine the percentage of the decrease of this time and, therefore, the gain in productivity of the platform, which is undoubtedly an attractive benefit for receipt companies, during harvesting periods, in which the line for unloading is quite large.

\subsection{Discounted Payback}

In order to acquire the necessary equipment to adapt the unloading platform with a frequency inverter starter system, considering the previously described equipment, an investment of approximately ten thousand reais ( $\mathrm{R} \$ 10,000.00)$ would be required. This value will be used as a reference for system deployment.

Another value considered is the cost of energy avoided in one year, provided by the frequency inverter, i.e., the annual net return of the investment required for the installation of the frequency inverter. Cash flows, which represent the initial investment (down arrow) and avoided costs (up arrows), are shown in Figure 8.

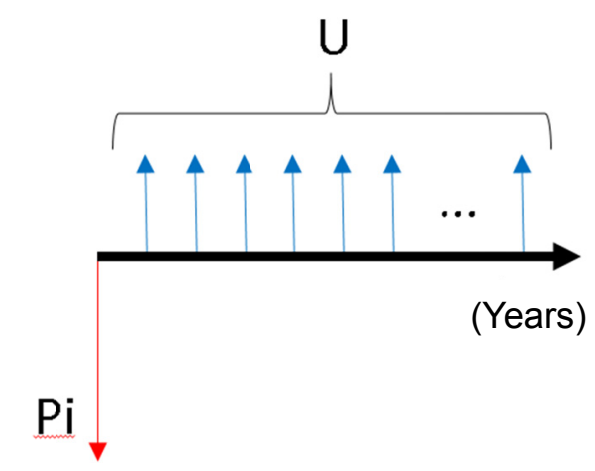

Figure 8. Uniform series containing initial investment and annual net return

This series can be interpreted by Equation 15:

$$
\text { PAYBACK }_{\text {discounted }}=\frac{\operatorname{In}\left(\frac{U}{U-P \cdot T M A}\right)}{\operatorname{In}(1+\text { TMA })}
$$

Where, $\mathrm{U}=$ Annual cost of electricity avoided $(\mathrm{R} \$) ; \mathrm{Pi}=$ Initial investment made $(\mathrm{R} \$)$; TMA $=$ Minimum decimal attractiveness rate.

This calculation indicates the time of return of the invested capital, considering the time value of money. For the study, the minimum attractiveness rate of $6 \%$ per year was considered.

\section{Results and Discussion}

\subsection{Power and Performance of Platform Command Devices}

For the calculation of the Mechanical Power of the platform, Equation 1 was used. The data collected were as follows:

Total gross truck weight plus platform weight $(\mathrm{PT})=75.38$ metric tons;

Note. For these calculations, the heaviest truck among the samples (55.38 metric tons in PBT) was used.

Total time to tilt the platform $(\mathrm{t})=164 \mathrm{~s}$;

Total cylinder stroke $(\mathrm{CC})=6.92 \mathrm{~m}$;

Based on these data, the Mechanical Power needed to tilt the platform was: Pm2 $=31.17 \mathrm{~kW}$.

For the calculation of the Hydraulic Power, Equation 4 was used. The data collected were the following:

Flow (informed by the manufacturer) $(\mathrm{Q})=180 \mathrm{l} / \mathrm{min}$;

Pressure (measured on the manometer for tipping the truck) $($ Pre $)=130 \mathrm{kgf} / \mathrm{cm}^{2}$;

Based on these data, the Hydraulic Power required to tilt the platform was: $\mathrm{Ph}=32.88 \mathrm{~kW}$.

For the calculation of the Mechanical Power of the engine, Equation 5 was used: 
Electrical power $(\mathrm{Pel})=42.76 \mathrm{~kW}$;

Motor Performance $(\eta)=90 \%$;

Based on these data, the required Mechanical Power of the motor was: Pm1 $=38.48 \mathrm{~kW}$.

The value of the Electric Power (Pel) is the same used for the calculation of Pm1. This value was obtained by the energy analyzer but could also be calculated from the values of voltage, current and power factor obtained from the same equipment. Therefore, the electric power of the motor was: Pel $=42.76 \mathrm{~kW}$.

For the calculation of yields, Equations 7, 8 and 9 were used:

$\eta$ hydraulic pump $=85.45 \%$;

$\eta$ platform $=94.8 \%$;

$\eta$ total $=72.9 \%$.

\subsection{Results Obtained for Scenario 1}

Figure 9 shows the active power, collected in the started system, using a wye-delta switch.

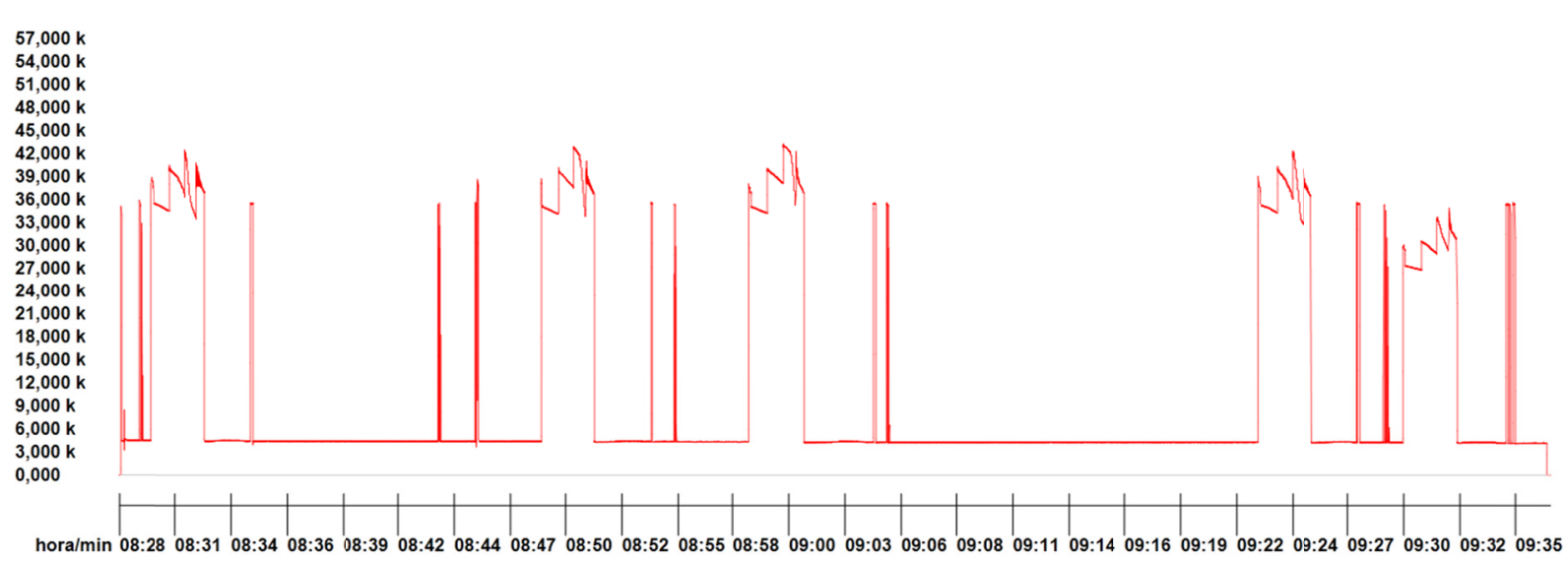

Figure 9. Active power graph for wye-delta starter system

It can be observed that, in the intervals in which the platform descends or even when it is inoperative, the motor is not turned off, implying unnecessary energy consumption. The power measured during these inoperative intervals was approximately $4.5 \mathrm{~kW}$.

Table 6 shows the values collected by the energy analyzer: 
Table 6. Electric quantities read by the energy analyzer in scenario 1

\begin{tabular}{|c|c|c|c|c|c|}
\hline Date & Start & \multicolumn{3}{|c|}{ End } & Duration \\
\hline $9 / 27 / 2017$ & $08: 28: 46 \mathrm{am}$ & \multicolumn{3}{|c|}{ 09:37:15 am } & 01:08:29 \\
\hline \multicolumn{6}{|l|}{ Voltage } \\
\hline Phase & Maximum & \multicolumn{3}{|c|}{ Minimum } & Mean \\
\hline $\mathrm{A}$ & 223.080 & \multicolumn{3}{|c|}{216.860} & 221.760 \\
\hline B & 223.830 & \multicolumn{3}{|c|}{217.690} & 222.430 \\
\hline $\mathrm{C}$ & 223.000 & \multicolumn{3}{|c|}{216.710} & 221.590 \\
\hline \multicolumn{6}{|l|}{ Current } \\
\hline Phase & Maximum & \multicolumn{3}{|c|}{ Minimum } & Mean \\
\hline A & 126.435 & \multicolumn{3}{|c|}{0} & 36.645 \\
\hline B & 124.144 & \multicolumn{3}{|c|}{0} & 35.209 \\
\hline $\mathrm{C}$ & 128.072 & \multicolumn{2}{|r|}{0} & & 36.006 \\
\hline \multicolumn{6}{|l|}{ Power } \\
\hline Phase & $\mathrm{kWh}$ & kVAh & & $\mathrm{kVAr}$ & F.P. \\
\hline A & 4.340 & 8.711 & & 7.553 & 0.498 \\
\hline B & 3.823 & 8.404 & & 7.484 & 0.455 \\
\hline $\mathrm{C}$ & 4.170 & 8.533 & & 7.445 & 0.489 \\
\hline TOTAL & 12.332 & 15.715 & & 22.483 & 0.481 \\
\hline
\end{tabular}

The active energy consumption during this time was $12.332 \mathrm{kWh}$.

Table 7 shows the energy index per metric ton, which was $35.44 .10-3 \mathrm{kWh} / \mathrm{ton}$.

Table 7. Calculation of the energy index per metric ton

\begin{tabular}{llll}
\hline Truck & PBT (metric ton) & PC (metric ton) & PL (metric ton) \\
\hline A & 54.26 & 16.50 & 37.76 \\
B & 53.86 & 16.62 & 37.24 \\
C & 51.14 & 16.92 & 34.22 \\
D & 55.38 & 16.32 & 39.06 \\
E & 33.28 & 10.64 & 22.64 \\
Total & 247.92 & 77.00 & 170.92 \\
PT (Total PBT + PP) & 347.92 & & \\
No. of CYCLES & 5 & & \\
Consumption (kWh) & 12.332 & & \\
kWh/ton & 0.0354449 & & \\
\hline
\end{tabular}

\subsection{Results Obtained for Scenario 2}

Figure 10 shows the active power, collected in the frequency inverter starter system. 


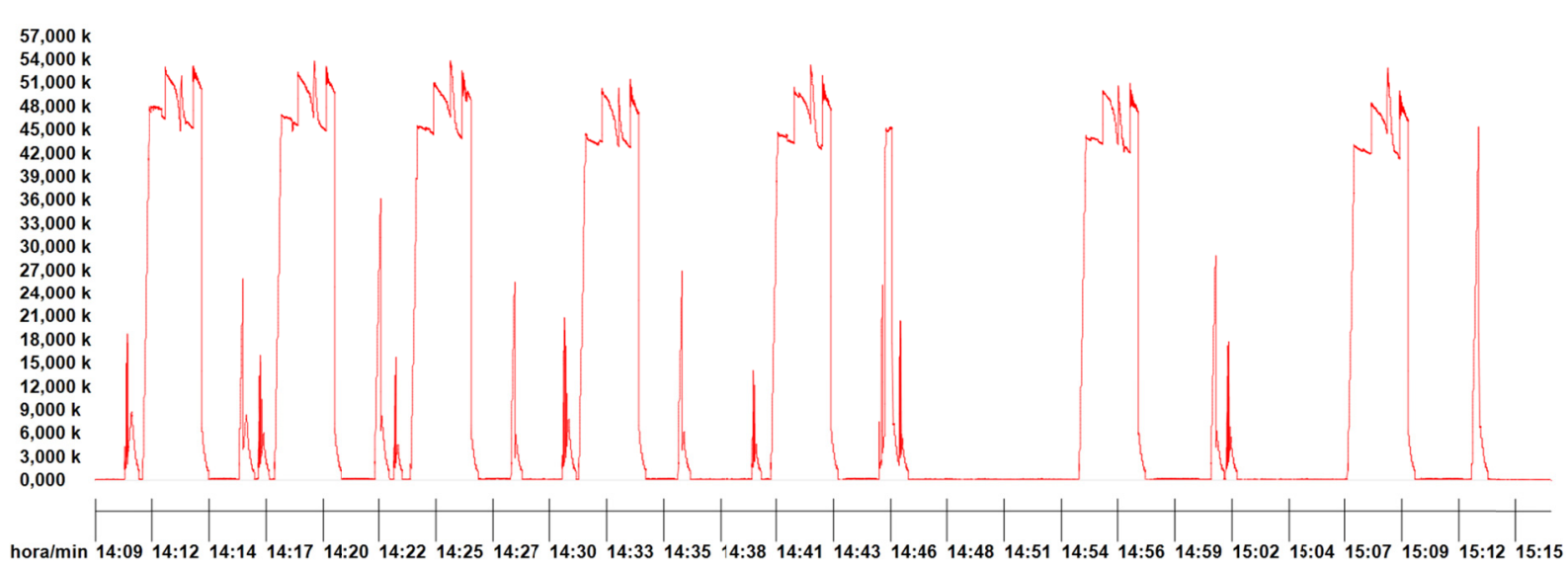

Figure 10. Active power chart for the frequency inverter starter

It is observed that, with the frequency inverter, the active power is practically zero during moments in which its use is not required; however, it has significantly higher power than the wye-delta system during use. This increase can be explained by the change in the operating point of the yield curve of the hydraulic pump.

Table 8 shows the values measured by the energy analyzer:

Table 8 . Electrical quantities read by the energy analyzer in scenario 2

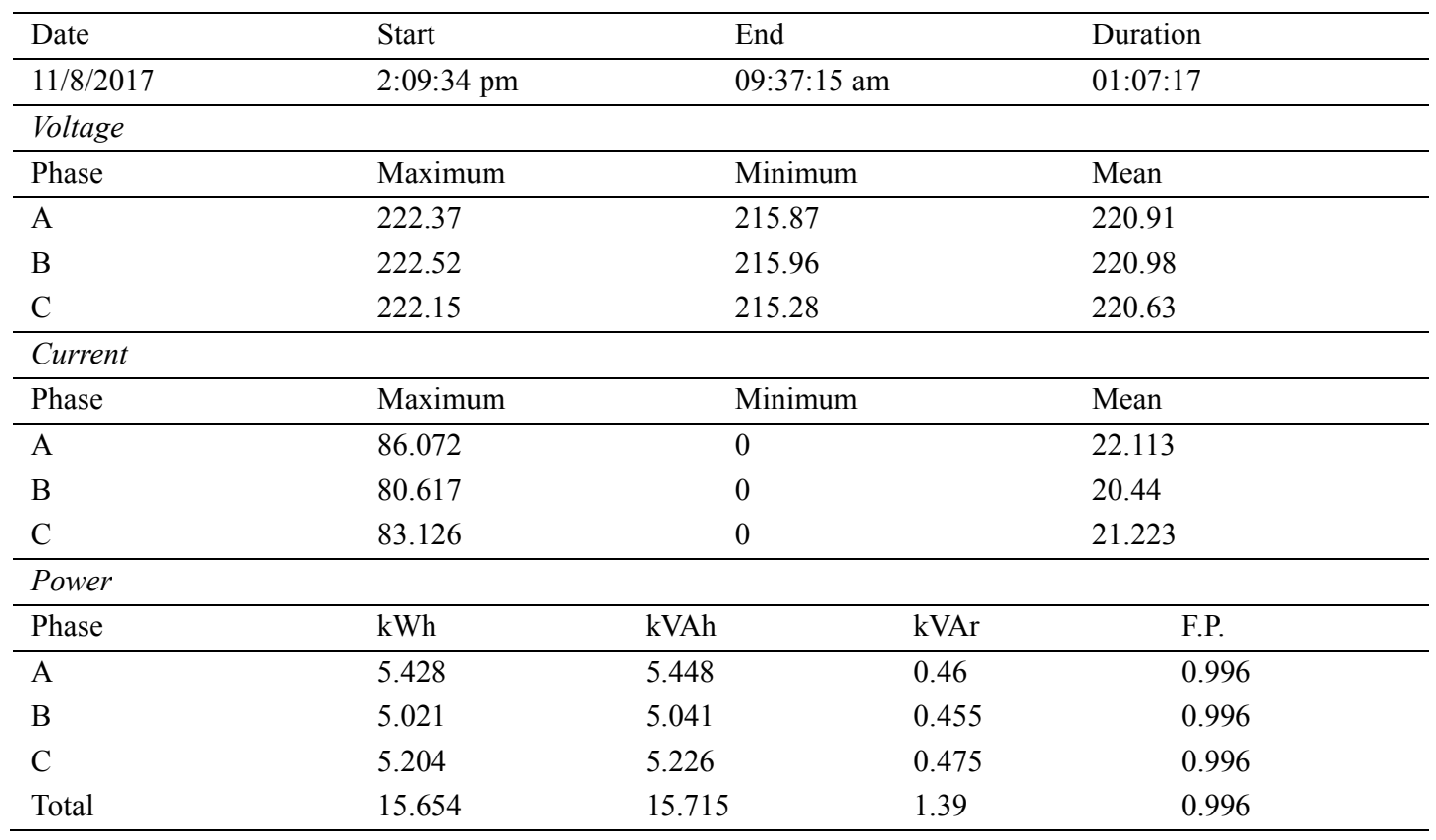

Active energy consumption during this time was $15.654 \mathrm{kWh}$.

Table 9 shows the energy index per metric ton, which was $32.78 .10-3 \mathrm{kWh} / \mathrm{ton}$. 
Table 9 . Electric quantities read by the energy analyzer in scenario 2

\begin{tabular}{llll}
\hline Truck & PBT (metric ton) & PC (metric ton) & PL (metric ton) \\
\hline F & 48.26 & 16.08 & 32.18 \\
G & 48.1 & 16.62 & 31.48 \\
H & 48.06 & 16.5 & 31.56 \\
$\mathrm{I}$ & 48.36 & 16.32 & 32.04 \\
$\mathrm{~J}$ & 48.36 & 16.4 & 31.96 \\
$\mathrm{~K}$ & 48.16 & 16.66 & 31.5 \\
$\mathrm{~L}$ & 48.22 & 16.08 & 32.14 \\
Total & 337.52 & 114.66 & 222.86 \\
PT $($ Total PTB + PP) & 477.52 & & \\
No. of CYCLES & 7 & & \\
CONSUMPTION $(\mathrm{kWh})$ & 15.654 & & \\
kWh/ton & 0.032782 & & \\
\hline
\end{tabular}

\subsection{Reducing Power Consumption and Improving Productivity}

Based on the data obtained, it can be observed that the amount of energy required to tip one metric ton is sensitively smaller in the system with the frequency inverter than in the system with the wye-delta switch.

Table 10 presents the TU (single tariff), created to calculate the value in reais for each $\mathrm{kWh}$ of energy, consumed by the unloading platform.

Table 10. Single Tariff (TU) calculation

\begin{tabular}{ll}
\hline Copel Energy Rate for September 2017 & \\
\hline Off-Peace Active Energy & $75803 \mathrm{kWh}$ \\
Total Invoice Amount & $\mathrm{R} \$ 66652.39$ \\
Single Tariff & 0.879284 \\
\hline
\end{tabular}

For the projection of the values obtained, the total average Gross Weight (PBT), Truck Weight (PC) and Net Weight (PL) of all trucks of the two experiments were calculated. These values are, respectively, 48.79 ton, 15.97 ton, and 32.82 ton.

Considering these values, it is possible to present Table 11, considering an estimate of the number of cycles in a month, PT (total weight tipped in one month), energy consumed in both scenarios, and energy avoided, if the frequency inverter were installed.

Table 11. Estimated consumption, energy amount avoided and costs

\begin{tabular}{|c|c|c|c|c|c|c|c|c|}
\hline \multirow[b]{2}{*}{ Month } & \multirow[b]{2}{*}{$\begin{array}{l}\text { Received (PL) } \\
\text { (ton) }\end{array}$} & \multirow[b]{2}{*}{$\begin{array}{l}\text { No. of } \\
\text { Cycles }\end{array}$} & \multicolumn{2}{|c|}{ Wye-Delta } & \multicolumn{2}{|c|}{ Inverter } & \multicolumn{2}{|c|}{ Amount avoided } \\
\hline & & & $\begin{array}{l}\text { PTmonth } \\
\text { (ton) }\end{array}$ & $\begin{array}{l}\text { ECmonth } \\
(\mathrm{kWh})\end{array}$ & $\begin{array}{l}\text { Vmonth } \\
\text { (R\$) }\end{array}$ & $\begin{array}{l}\text { ECmonth } \\
(\mathrm{kWh})\end{array}$ & $\begin{array}{l}\text { Vmonth } \\
(\mathrm{kWh})\end{array}$ & $\begin{array}{l}\text { Vmonth } \\
\text { (R\$) }\end{array}$ \\
\hline Oct $/ 16$ & 9407.06 & 287 & 19719.04 & 698.94 & 614.57 & 646.43 & 586.39 & 52.51 \\
\hline Nov/16 & 12837.68 & 391 & 26910.29 & 953.83 & 838.69 & 882.17 & 775.68 & 71.66 \\
\hline $\mathrm{Dec} / 16$ & 16735.33 & 510 & 35080.53 & 1243.43 & 1093.33 & 1150.01 & 1011.18 & 93.52 \\
\hline Jan/17 & 6509.60 & 198 & 13645.40 & 483.66 & 425.27 & 447.32 & 393.32 & 36.34 \\
\hline Feb/17 & 21120.50 & 644 & 44272.70 & 1569.24 & 1379.81 & 1451.34 & 1276.14 & 117.9 \\
\hline Mar/17 & 9135.70 & 278 & 19150.22 & 678.78 & 596.84 & 627.78 & 552 & 51 \\
\hline Apr/17 & 1713.98 & 52 & 3592.84 & 127.35 & 111.97 & 117.78 & 103.56 & 9.57 \\
\hline May/17 & 8732.40 & 266 & 18304.82 & 648.81 & 570.49 & 600.07 & 527.63 & 48.75 \\
\hline Jun/17 & 15780.14 & 481 & 33078.26 & 1172.46 & 1030.92 & 1084.37 & 953.47 & 88.09 \\
\hline $\mathrm{Jul} / 17$ & 28114.16 & 857 & 58932.79 & 2088.87 & 1836.71 & 1931.93 & 1698.71 & 156.94 \\
\hline Aug/17 & 9134.98 & 278 & 19148.71 & 678.72 & 596.79 & 627.73 & 551.95 & 50.99 \\
\hline Sep/17 & 7769.38 & 237 & 16286.14 & 577.26 & 507.58 & 533.89 & 469.44 & 43.37 \\
\hline Total & 146990.91 & 4479 & 308121.73 & 10921.35 & 9602.97 & 10100.81 & 8881.48 & 820.55 \\
\hline
\end{tabular}


Based on these data, the net annual return, with the installation of the frequency inverter, is seven hundred and twenty-one reais and forty-nine centavos (R $\$ 721.49)$.

Another factor observed was the increase in productivity, with the inverter adjusted to operate at $20 \%$ above the nominal rotation. In this case, the platform took 2 minutes and 14 seconds to be lifted, the time being 2 minutes and 44 seconds previously. There is an increase of almost $19 \%$ in the tipping speed, and this reduction in total time can be very attractive in periods when there are many trucks to be unloaded.

\subsection{Discounted Payback}

After obtaining all the necessary data, the calculation of the discounted payback was made based on Equation 32, presenting a result for the return of the investment equal to 31 years. Considering that this time of return is very long, even well above the service life of the equipment that would be installed, it is concluded that the investment is economically unfeasible, for the particular conditions presented in this paper.

\section{Conclusion}

The application of the frequency inverter to reduce power consumption in the unloading platform is real, as the inverter has a relatively better energy efficiency result than the conventional wye-delta start system. The efficiency calculations made it possible to understand that this efficiency can be improved by applying better performance components, such as high-performance motors, hydraulic pumps with lower losses, etc.

The electric power required to tilt the platform is smaller in the wye-delta starter system compared to the frequency inverter, but this system operates continuously even at unnecessary times, during which the frequency inverter has a small advantage, as its consumption is practically zero. When comparing these two situations, the frequency inverter shows significantly lower energy consumption per metric ton tipped than the conventional system.

In addition to lower power consumption, the frequency inverter makes it possible to increase the flow rate of the hydraulic pump, as it is possible to increase the nominal rotation of the three-phase induction motor. This can be a major advantage for the storage units and can become an important device against the extended lines and delays in receiving the product. The inverter, in turn, can expedite by up to $19 \%$ the unloading speed, when compared to the current system.

Nevertheless, when the discounted payback (approximately 31 years) was calculated, it was found that the installation of a frequency inverter and a PLC for the control of the hydraulic unit is not economically feasible, as its investment can be considered high, compared to the annual avoided value that the system provides. This value is much higher than the service life of the equipment used, which is usually 10 to 15 years, making its investment unfeasible.

As suggestions for future work, it is important to evaluate a hydraulic unit for unloading platforms, using a high-efficiency motor, as well as the study of the formation of lines in storage units, in order to evaluate the impact of the agility of the process.

\section{References}

AB Agrobrasil. (2017). Dados Históricos e Técnicos da Empresa. http://www.abagrobrasil.com.br/empresa.php

CONAB (Companhia Nacional de Abastecimento). (2017). Acompanhamento da Safra Brasileira de Grãos. V.4 Safra 2016/2017-N. 10-Décimo Levantamento Julho 2017. Retrieved from http://www.conab.gov.br/ OlalaCMS/uploads/arquivos/17_07_12_11_17_01_boletim_graos_julho_2017.pdf

EMBRAPA (Empresa Brasileira de Pesquisa Agropecuária). (2017). Soja em números (Safra 2016/2017). Retrieved from https://www.embrapa.br/soja/cultivos/soja1/dados-economicos

Portal Brasil. (2017). Economia e Emprego-Agroindústria. Retrieved from http://www.brasil.gov.br/ economia-e-emprego/2011/02/agroindustria-brasileira-cresceu-4-7

SAUR. (2017). Plataforma de Descarga 21 metros. Retrieved from http://www.saur.com.br/pt/agricola/ plataformas-de-descarga-tombadores/plataforma-de-descarga-traseira-21-metros

Silva, L. C. da. (2010). Estruturas para Armazenagem de Grãos a Granel. Editora da Universidade Federal do Espirito Santo. Vitoria, ES: Federal University of Espirito Santo.

UN (United Nations). (2010). The secretary-General's Advisory Group on Energy and Climate Change, Energy for a sustainable future: Re-port and Recommendations. New York, NY: United Nations. 


\section{Copyrights}

Copyright for this article is retained by the author(s), with first publication rights granted to the journal.

This is an open-access article distributed under the terms and conditions of the Creative Commons Attribution license (http://creativecommons.org/licenses/by/4.0/). 